\title{
Prediction of genotoxic potential of cosmetic ingredients by an in silico battery system consisting of a combination of an expert rule-based system and a statistics-based system
}

\author{
Maki Aiba née Kaneko, Morihiko Hirota, Hirokazu Kouzuki and Masaaki Mori \\ Shiseido Research Center, Shiseido Co., Ltd., 2-2-1 Hayabuchi, Tsuzuki-ku, Yokohama-shi 224-8558, Japan
}

(Received November 13, 2014; Accepted December 3, 2014)

\begin{abstract}
Genotoxicity is the most commonly used endpoint to predict the carcinogenicity of chemicals. The International Conference on Harmonization (ICH) M7 Guideline on Assessment and Control of DNA Reactive (Mutagenic) Impurities in Pharmaceuticals to Limit Potential Carcinogenic Risk offers guidance on (quantitative) structure-activity relationship ((Q)SAR) methodologies that predict the outcome of bacterial mutagenicity assay for actual and potential impurities. We examined the effectiveness of the (Q)SAR approach with the combination of DEREK NEXUS as an expert rule-based system and ADMEWorks as a statistics-based system for the prediction of not only mutagenic potential in the Ames test, but also genotoxic potential in mutagenicity and clastogenicity tests, using a data set of 342 chemicals extracted from the literature. The prediction of mutagenic potential or genotoxic potential by DEREK NEXUS or ADMEWorks showed high values of sensitivity and concordance, while prediction by the combination of DEREK NEXUS and ADMEWorks (battery system) showed the highest values of sensitivity and concordance among the three methods, but the lowest value of specificity. The number of false negatives was reduced with the battery system. We also separately predicted the mutagenic potential and genotoxic potential of 41 cosmetic ingredients listed in the International Nomenclature of Cosmetic Ingredients (INCI) among the 342 chemicals. Although specificity was low with the battery system, sensitivity and concordance were high. These results suggest that the battery system consisting of DEREK NEXUS and ADMEWorks is useful for prediction of genotoxic potential of chemicals, including cosmetic ingredients.
\end{abstract}

Key words: Mutagenicity, Genotoxicity, In silico, Cosmetic ingredient, INCI, Decision tree

\section{INTRODUCTION}

Genotoxicity tests, which are generally short-term tests, are useful to examine the genotoxic potential of chemicals, and to predict potential carcinogenicity. In the development of materials, such as drugs, pesticides, food additives and cosmetic ingredients, many candidate compounds are investigated by means of genotoxicity tests as a part of their safety evaluation (Zeiger, 2001). The Ames test is the most widely used assay to assess the mutagenic potential of chemicals (Ames et al., 1973; McCann et al., 1975; Sugimura et al., 1976; Purchase et al., 1978). The chromosomal aberration (CA) and the in vitro micronucleus (vit $\mathrm{MN}$ ) tests are used to detect clastogenic potential (Ishidate et al., 1998; Matsushima et al., 1999; Sobol et al., 2012). Chemicals that give positive results in such in vitro tests are usually further evaluated by means of in vivo genotoxicity tests, which are considered as the gold standard for genotoxicity testing (Hayashi et al., 1988, 1990; Thybaud et al., 2003; Tice et al., 2000; Mori et al., 1999). Evaluation with the Ames test and the CA test is regarded as an important early step in the development of new compounds, but it is impossible in practice to perform these assays for all candidate chemicals, because the experimental procedures are time-consuming. In addition, increasing public concern regarding animal welfare and animal rights means that implementation of in vivo genotoxicity tests is becoming difficult even for compounds that show positive in vitro genotoxicity tests.

In silico methods can circumvent these difficulties, and

Correspondence: Masaaki Mori (E-mail: masaaki.mori@to.shiseido.co.jp) 
are becoming more widely employed in the field of toxicology. Already, in silico models have been used for prediction of organ-specific toxicities, such as hepatotoxicity (Contrera et al., 2003), cardiotoxicity (Pearlstein et al., 2003), and nephrotoxicity (Myshkin et al., 2012), as well as for prediction of biochemical toxicities, such as plasma protein binding (Li et al., 2011), cytochrome P450 inhibition (Wanchana et al., 2003), blood-brain barrier permeability (Martins et al., 2012), and ADME (Hosea and Jones, 2013). They are also being used for prediction of genomic toxicities, such as genotoxicity and carcinogenicity (Hillebrecht et al., 2011), and reproductive and developmental toxicity (Worth et al., 2011). The International Conference on Harmonization (ICH) M7 Guideline on Assessment and Control of DNA Reactive (Mutagenic) Impurities in Pharmaceuticals to Limit Potential Carcinogenic Risk reached step 4 of the ICH Process in June 2014 (ICH, 2014). This guideline accepts the analysis of structure-activity relationships (SAR) using in silico methods for mutagenic hazard assessment of actual and potential impurities if data for bacterial mutagenicity are not available. The guideline states that the assessment should be conducted using two different in silico approaches, i.e., an expert rule-based system and a statistics-based system (Sutter et al., 2013), because these approaches complement each other and are suitable to predict the outcome of the Ames test.

For the present work, we selected DEREK NEXUS as an expert rule-based system (Greene et al., 1999) and ADMEWorks as a statistics-based system (Hayashi et al., 2005), and compared the utility of each computational tool and the battery system consisting of both tools for prediction of not only mutagenic potential in the Ames test, but also genotoxic potential as reflected by mutagenicity in the Ames test and clastogenicity in the CA test, the vit $\mathrm{MN}$ test or the mouse lymphoma assay (MLA), using a data set of 342 chemicals extracted from three reports (Kirkland et al., 2005; Ashby and Tennant, 1988, 1991). We also applied this method for prediction of the mutagenic potential and genotoxic potential of 41 cosmetic ingredients listed in the International Nomenclature of Cosmetic Ingredients (INCI) (de Groot and Weijland, 1997) among the 342 chemicals, to see whether or not this method is useful for prediction of the genotoxic potential of cosmetic ingredients. We propose a decision tree including in silico methodology to evaluate genotoxic potential of cosmetic ingredients.

\section{MATERIALS AND METHODS}

\section{Data Sets}

Three hundred and forty-two structurally diverse general industrial chemicals, for which clear evaluation results of the Ames test and at least one of the CA test, the vit $\mathrm{MN}$ test and the MLA are available, were extracted from the literature (Kirkland et al., 2005; Ashby and Tennant, 1988, 1991). Genotoxicity of these chemicals had been evaluated based on the results in these tests. When the result of the CA test of a chemical was unavailable, the evaluation results in the vitMN test and the MLA were used instead as tests for clastogenicity. When either mutagenicity or clastogenicity was positive, genotoxicity was treated as positive. When both evaluation results were negative, genotoxity was treated as negative. In addition, 41 cosmetic ingredients listed in INCI were extracted from the whole data set, in order to examine whether our approach was applicable to cosmetic ingredients. The evaluation results of the Ames test, the CA test, the vit $\mathrm{MN}$ test, the MLA, and genotoxicity in these data sets are shown in Table 1 .

\section{In silico prediction systems used}

In this work, we used DEREK NEXUS (Lhasa Ltd., Leeds, UK) version 3.0.1, which is an expert rule-based system (Greene et al., 1999), and ADMEWorks Predictor (Fujitsu Kyushu Systems Ltd., Fukuoka, Japan) version 7.9.0.0, which is a statistics-based system (Hayashi et al., 2005). For DEREK NEXUS, 'Mutagenicity', which had 97 alerts, was selected as an endpoint for the prediction of mutagenic potential. 'Mutagenicity', 'Carcinogenicity', 'Chromosome damage', 'Genotoxicity' and 'Photomutagenicity', which had 97, 82, 95, 5 and 3 alerts, respectively, were selected as endpoints for the prediction of genotoxic potential. For ADMEWorks, 'Ames' was selected as an endpoint for the prediction of mutagenic potential. 'Ames' and 'Chromosomal aberrations' were selected as endpoints for the prediction of genotoxic potential.

\section{Definition of negative and positive responses for in silico methods}

Definitions of negative and positive predictions in DEREK NEXUS, ADMEWorks, and the battery system consisting of DEREK NEXUS and ADMEWorks were as follows. When the prediction in DEREK NEXUS was 'certain', 'probable' or 'plausible', it was regarded as positive, and when the prediction in the system was 'equivocal', 'doubted', 'improbable', 'impossible' or 'no alert', it was regarded as negative. When the prediction in ADMEWorks was 'positive', it was regarded as positive, 
In silico prediction methods for genotoxicity of cosmetic ingredients

Table 1. Data sets of chemicals.

A.

\begin{tabular}{lccccc}
\hline & Ames & CA & vit MN & MLA & Genotoxicity* \\
\hline Positive & 249 & 148 & 9 & 21 & 285 \\
Negative & 93 & 73 & 1 & 4 & 57 \\
\hline Total & 342 & 221 & 10 & 25 & 342 \\
\hline
\end{tabular}

B.

\begin{tabular}{lccccc}
\hline & Ames & CA & vitMN & MLA & Genotoxicity* \\
\hline Positive & 17 & 20 & 0 & 0 & 24 \\
Negative & 24 & 18 & 1 & 1 & 17 \\
\hline Total & 41 & 38 & 1 & 1 & 41
\end{tabular}

Three hundred and forty-two structurally diverse chemicals for which evaluation results using the Ames test, and at least one of the CA test, the vitMN test and the MLA have been reported (Kirkland et al., 2005; Ashby and Tennant, 1988, 1991) were extracted for the data set. The values are the numbers of chemicals evaluated by each test for the whole data set of general industrial chemicals (A) and for the subset of INCI-listed chemicals (B).

*: The genotoxicity evaluation was based on the results of the Ames test, the CA test, the vitMN test and the MLA. When the evaluation result of the CA test of a chemical was not available, the evaluation results in the vitMN test and the MLA of the chemical were added to the data set and used instead of the CA test as tests for clastogenicity. When either or both of the Ames test and the test for clastogenicity were positive, genotoxicity was treated as positive. When both of these evaluation results were negative, genotoxity was treated as negative.

and when the prediction in the system was 'negative', it was regarded as negative. When one of the predictions in DEREK NEXUS and ADMEWorks in the battery system was positive, the prediction by the battery system was treated as positive, and when both of the predictions were negative, the prediction by the battery system was treated as negative.

In the definition of negative and positive for mutagenic potential and genotoxic potential, when the prediction of the Ames test was positive, mutagenic potential was treated as positive, and when it was negative, mutagenic potential was treated as negative. When at least one prediction result of the tests related to genotoxicity or carcinogenicity was positive, genotoxic potential was treated as positive, and when all of these predictions were negative, genotoxic potential was treated as negative.

\section{Definition of parameters}

Sensitivity was defined as the ratio of the number of chemicals predicted as positive by in silico method(s) to the number of chemicals reported as positive after subtraction of inapplicable chemicals for mutagenic or genotoxic chemicals. Specificity was defined as the ratio of the number of chemicals predicted as negative by in silico method(s) to the number of chemicals reported as negative after subtraction of inapplicable chemicals for nonmutagenic or non-genotoxic chemicals. Concordance was defined as the ratio of the number of chemicals classi- fied into the same classification, positive or negative, in the in silico prediction and genotoxicity test results to the number after subtraction of inapplicable chemicals from the total number of chemicals. Applicability was defined as the ratio of the number of chemicals evaluated by in silico method to the total number of chemicals.

\section{RESULTS}

\section{Evaluation and prediction of genotoxicity of data set chemicals}

Table 2 summarizes the evaluation results for chemicals in the data set (Kirkland et al., 2005; Ashby and Tennant, 1988, 1991) and the in silico prediction results for mutagenic potential and genotoxic potential obtained with DEREK NEXUS, ADMEWorks and the battery system. The numbers of positive evaluation and positive in silico prediction results were greater than the numbers of negative evaluation and negative in silico prediction results, respectively.

\section{Prediction of mutagenic potential of general industrial chemicals}

Table 3 summarizes the results of prediction of mutagenic potential of general industrial chemicals by DEREK NEXUS, ADMEWorks and the battery system. DEREK NEXUS showed the highest specificity (84\%) and its applicability was $100 \%$, while ADMEWorks showed 
M. Aiba née Kaneko et al.

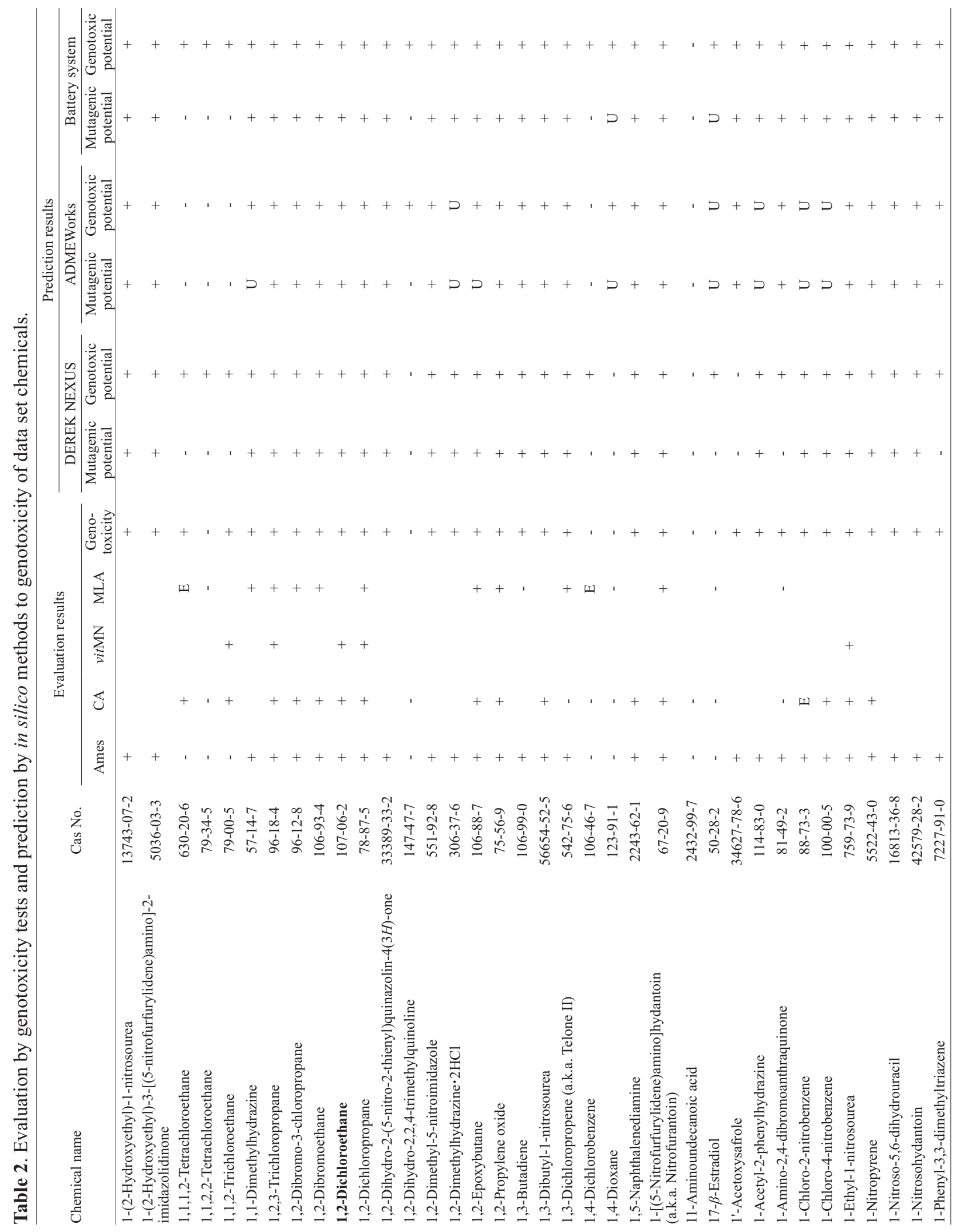

Vol. 40 No. 1 
In silico prediction methods for genotoxicity of cosmetic ingredients

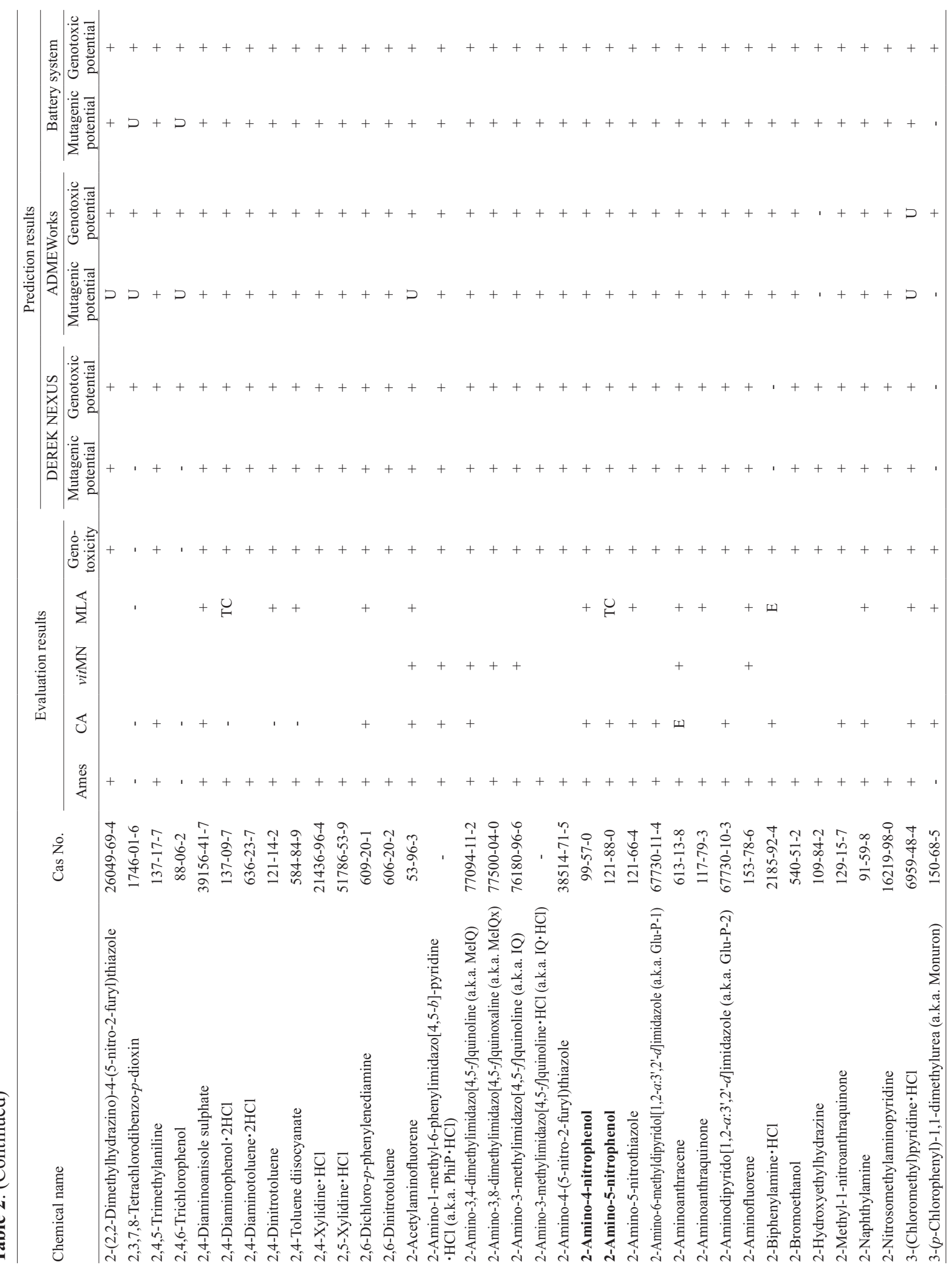


M. Aiba née Kaneko et al.

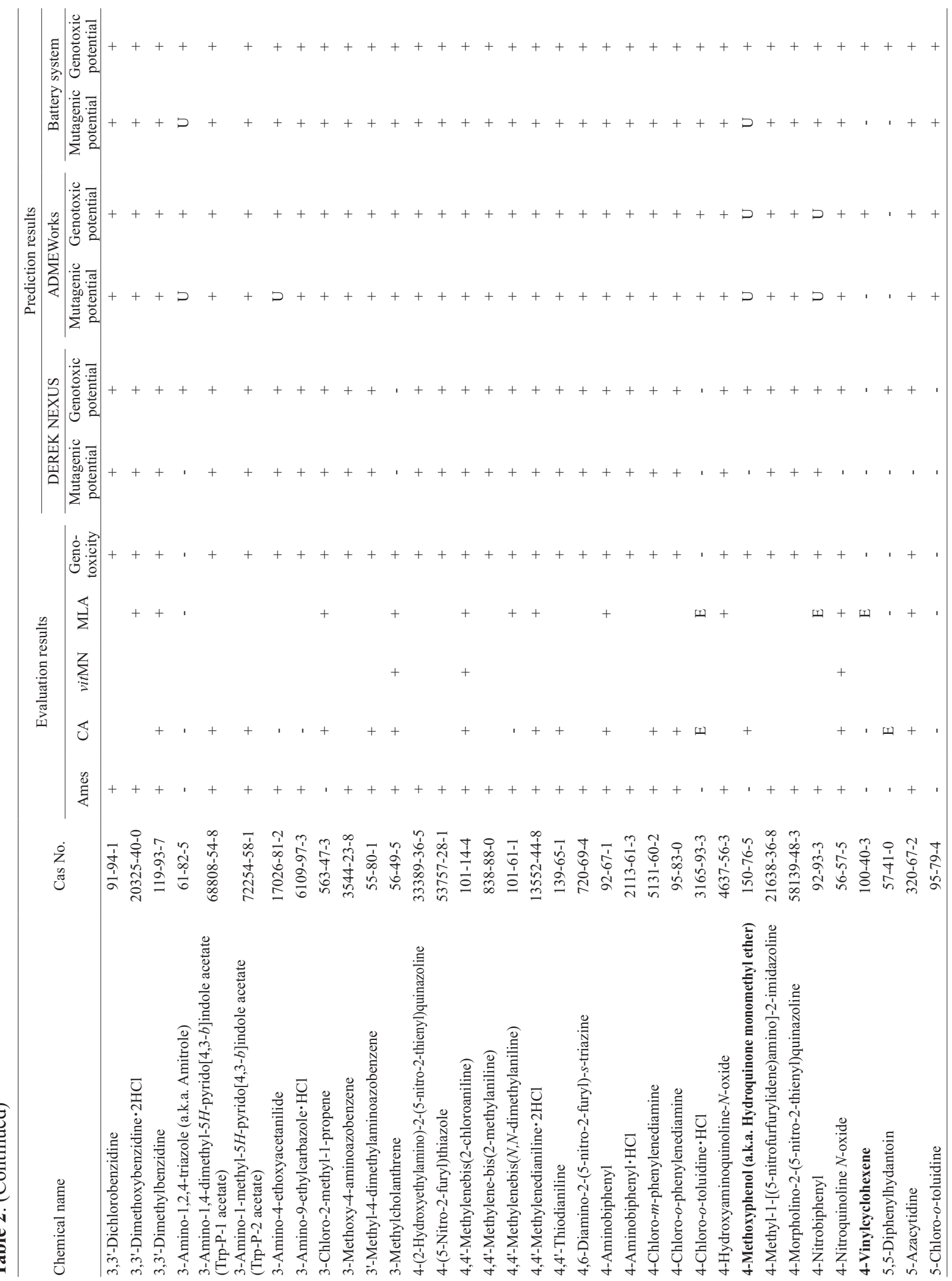

Vol. 40 No. 1 
In silico prediction methods for genotoxicity of cosmetic ingredients

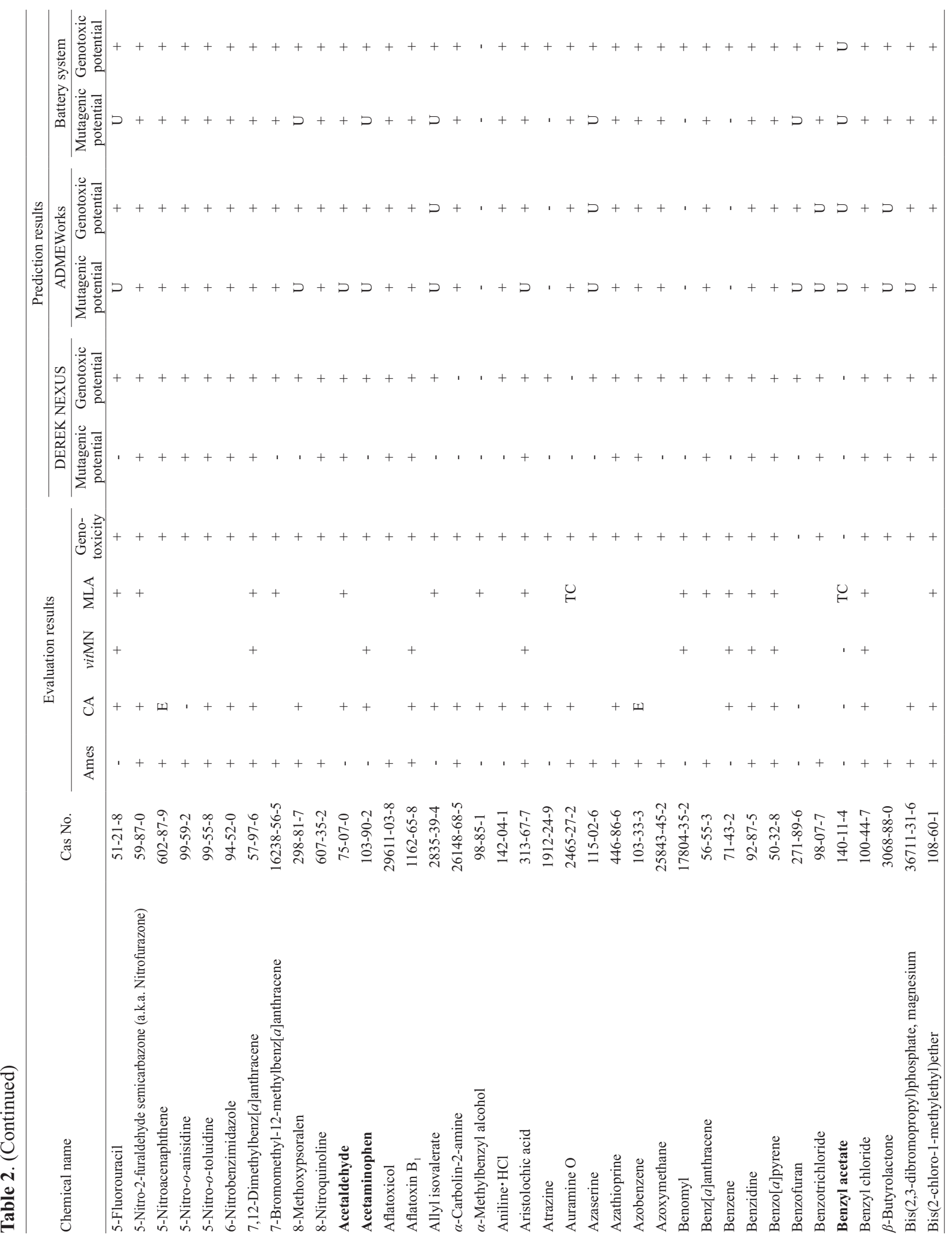


M. Aiba née Kaneko et al.

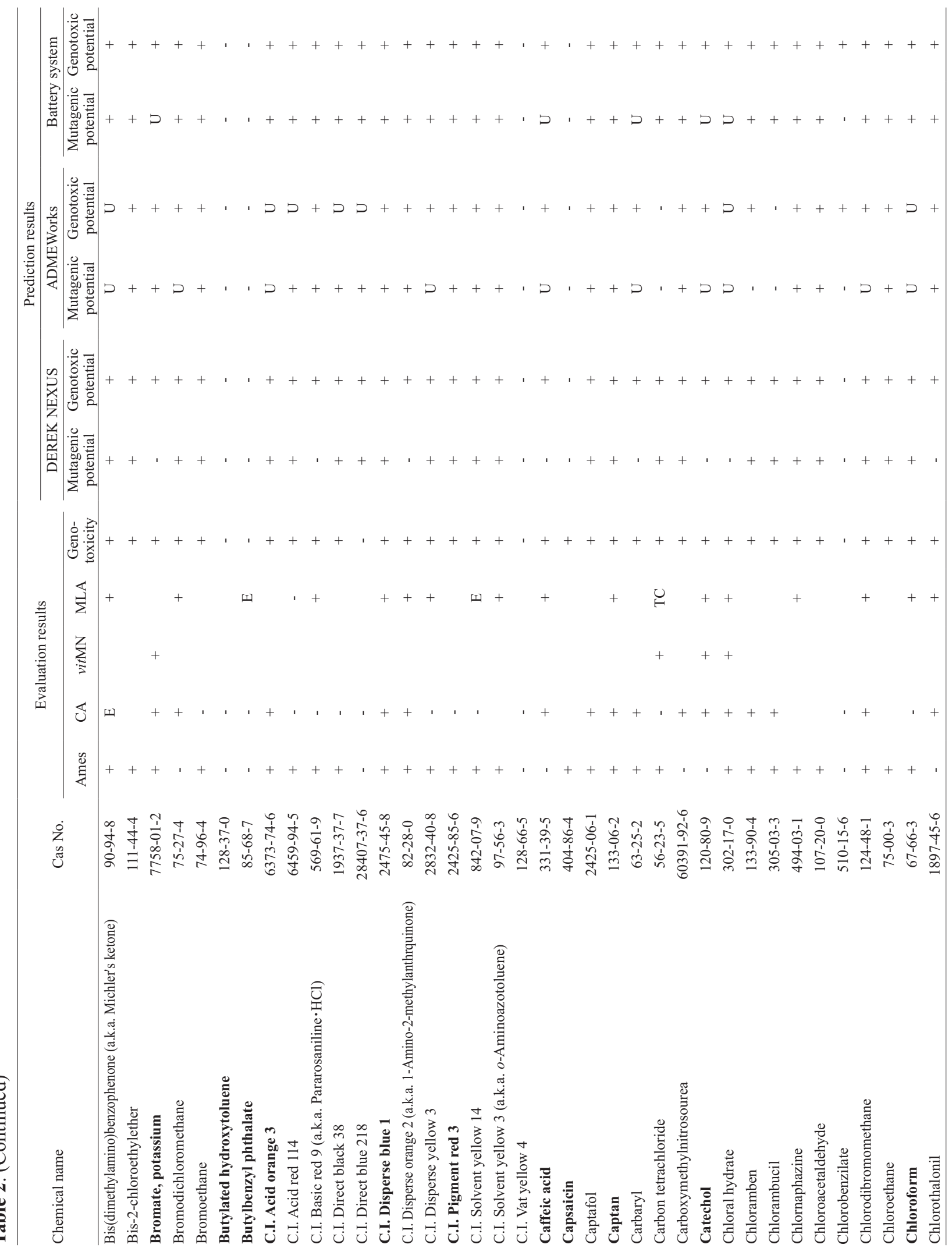

Vol. 40 No. 1 
In silico prediction methods for genotoxicity of cosmetic ingredients

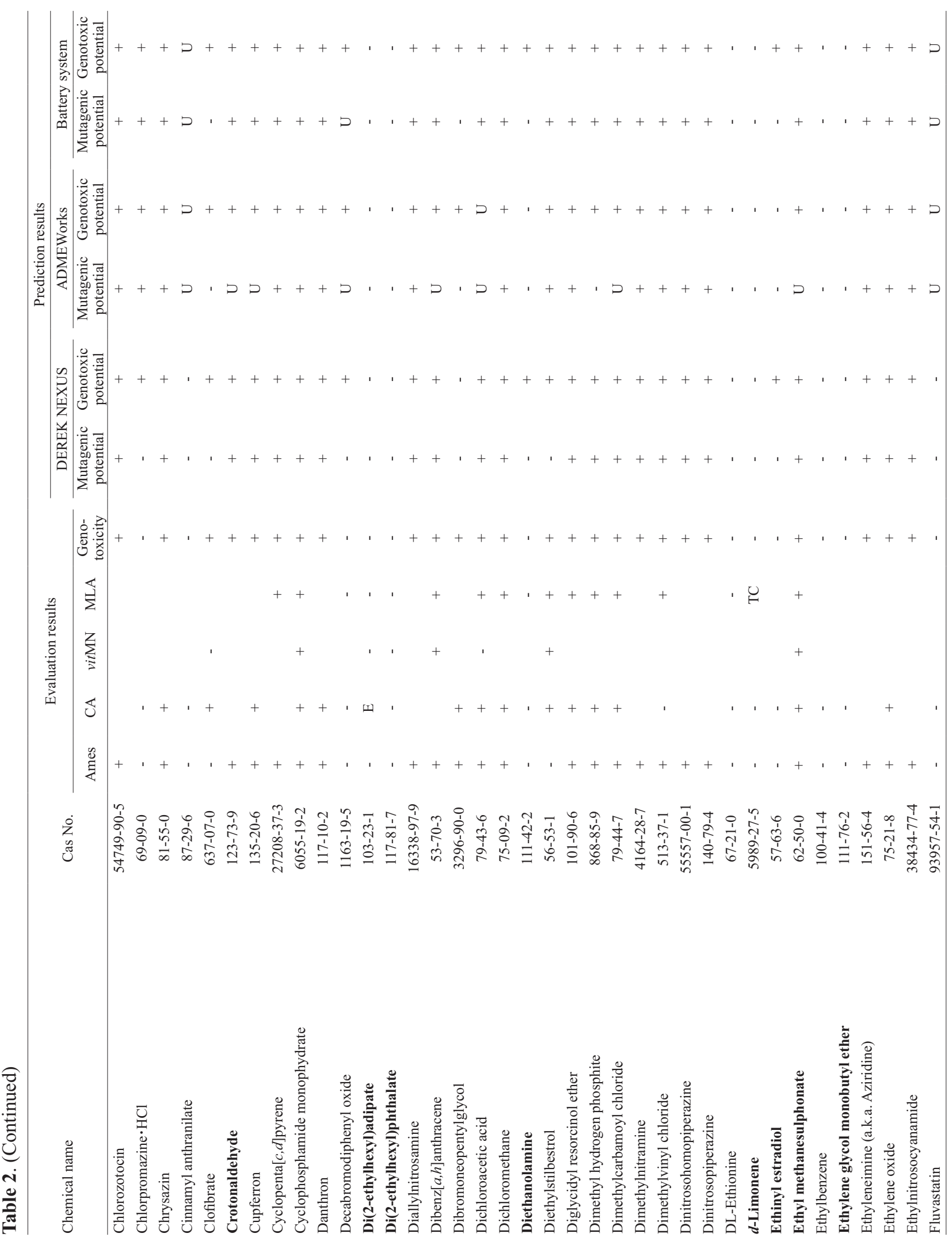


M. Aiba née Kaneko et al.

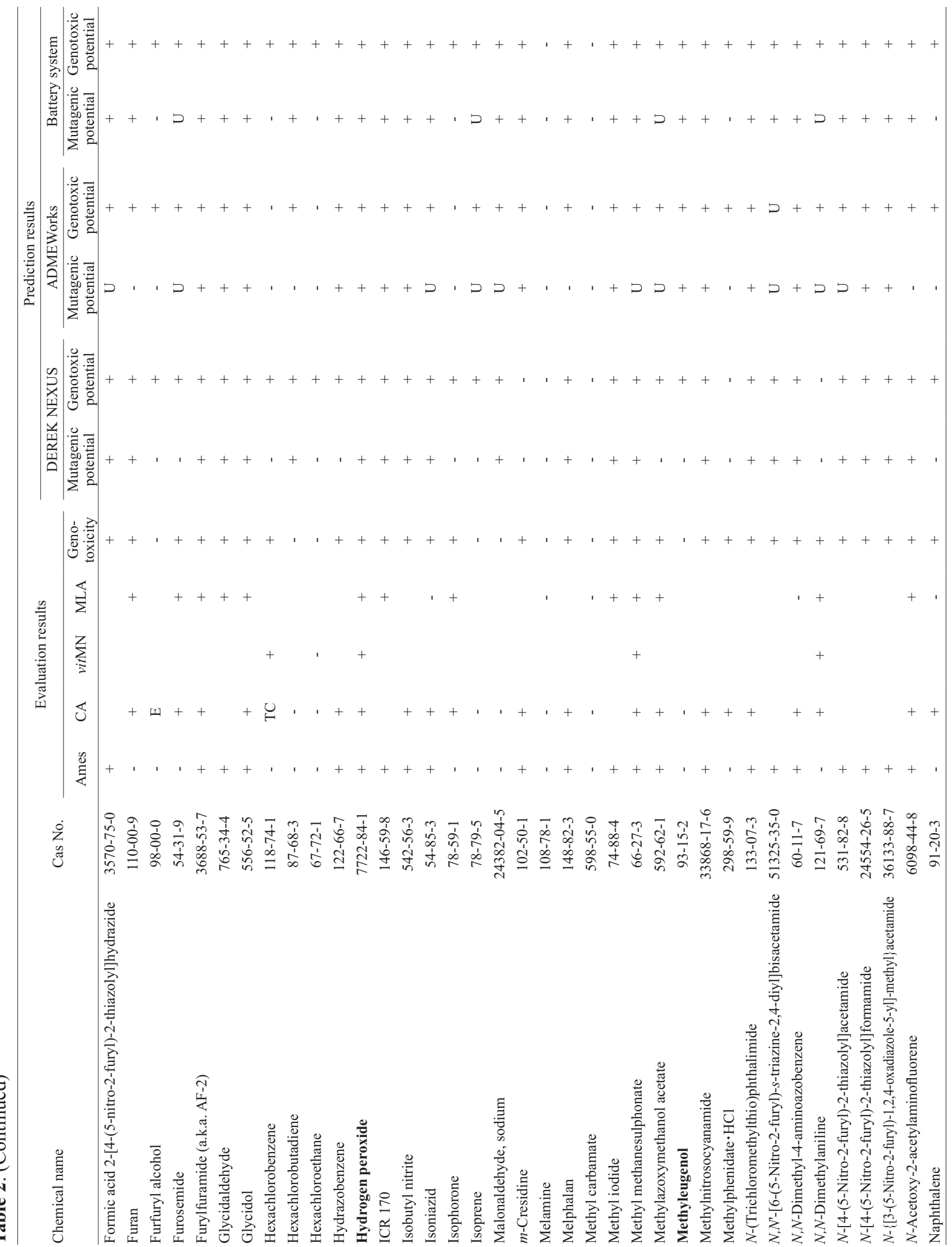

Vol. 40 No. 1 
In silico prediction methods for genotoxicity of cosmetic ingredients

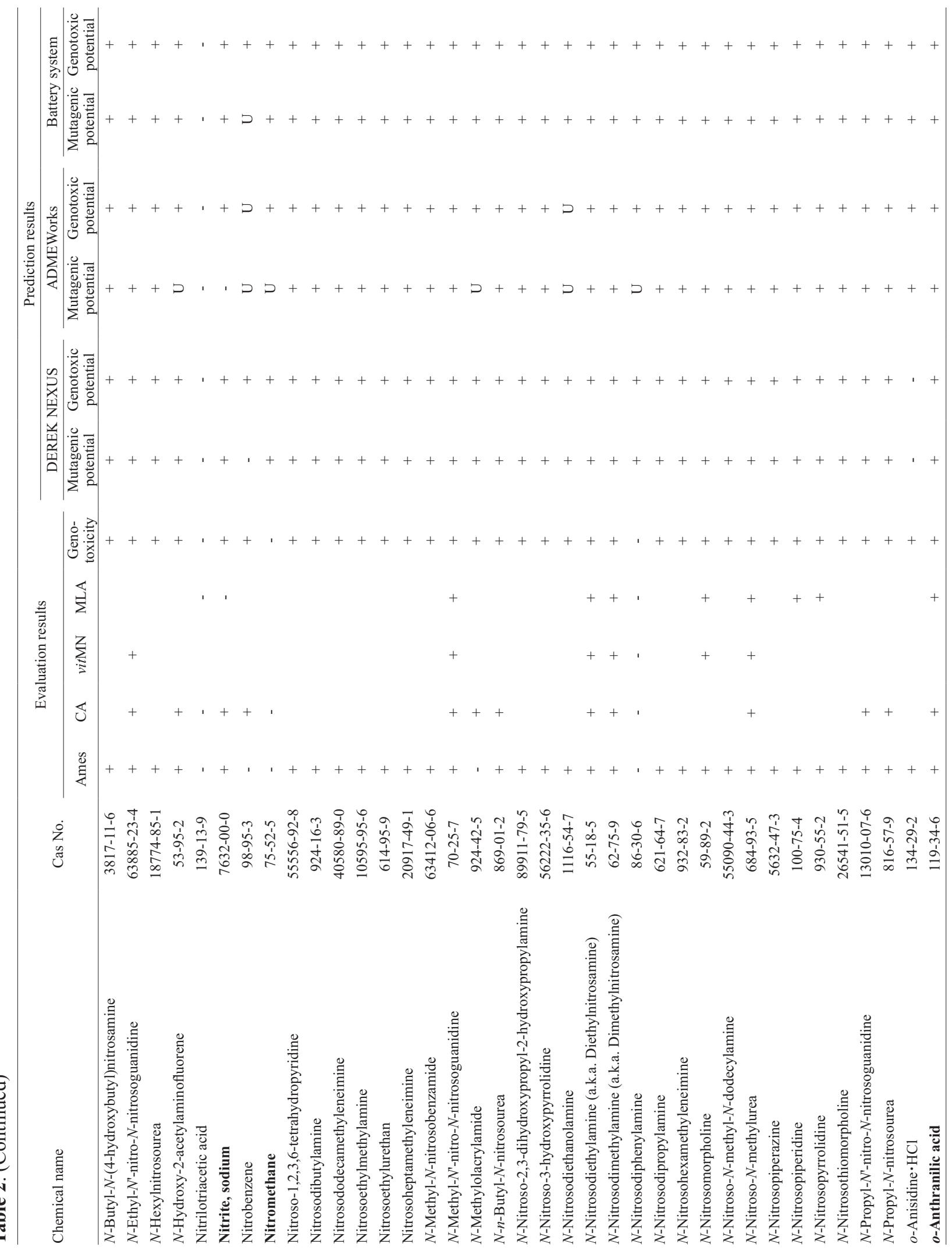


M. Aiba née Kaneko et al.

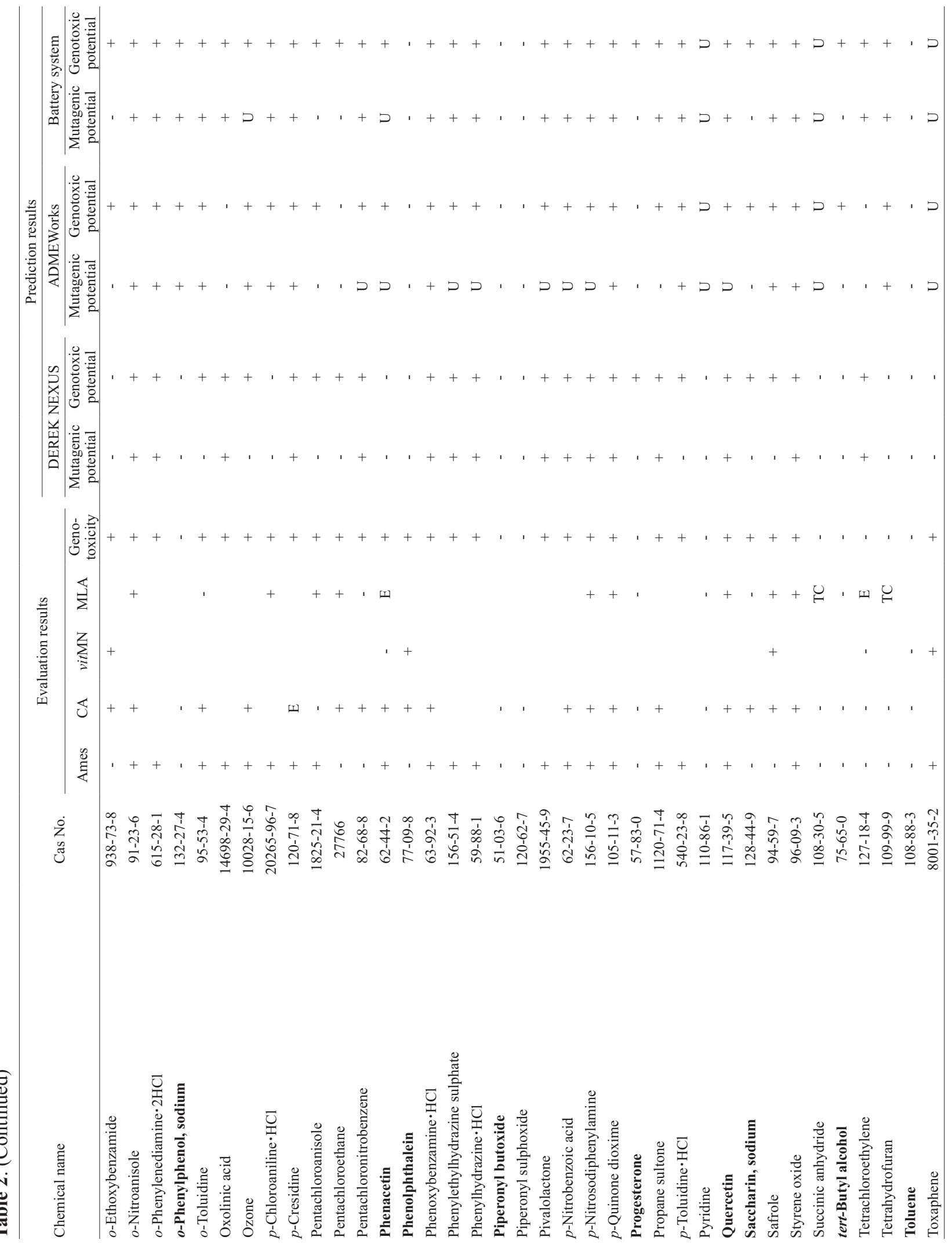

Vol. 40 No. 1 
In silico prediction methods for genotoxicity of cosmetic ingredients

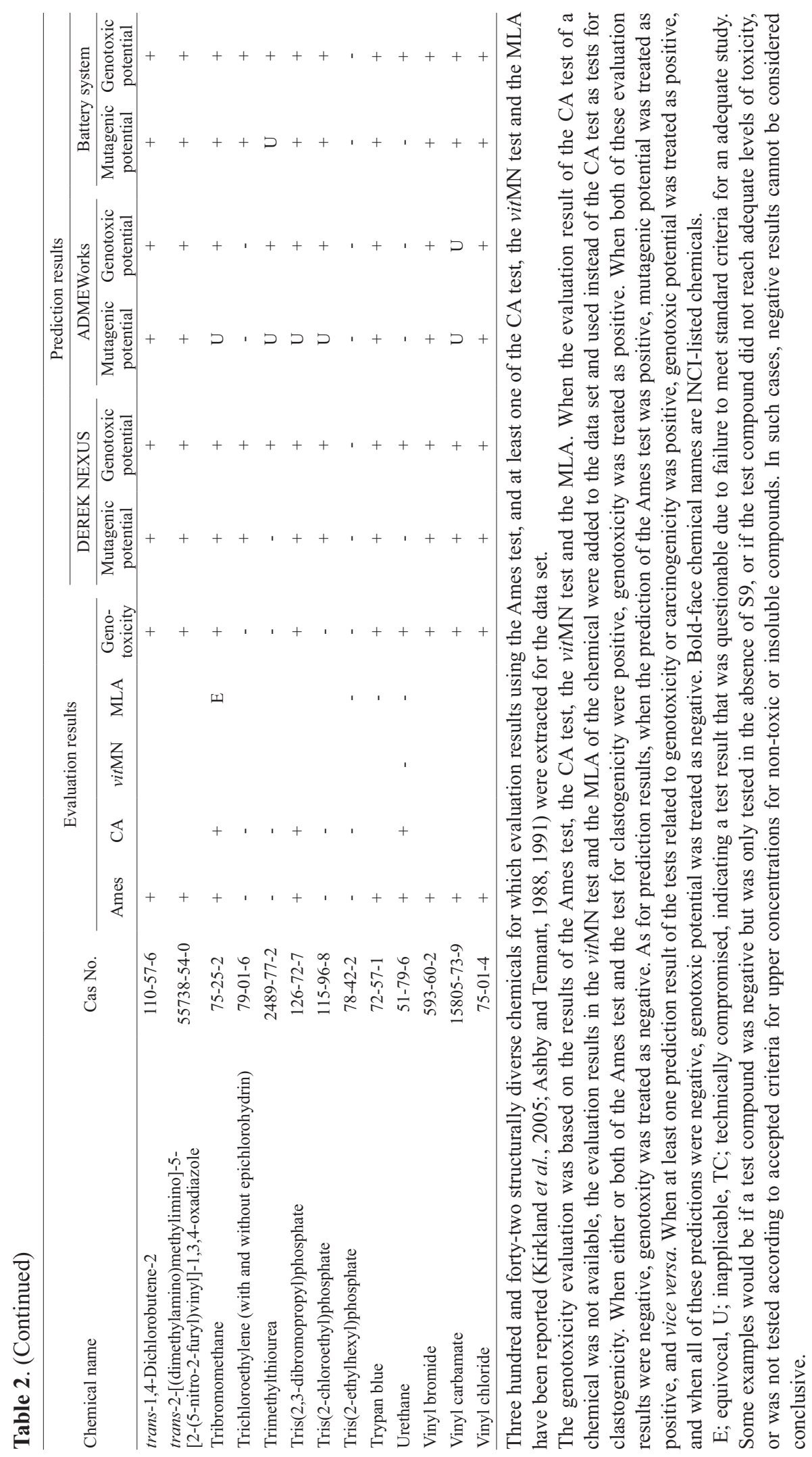


higher sensitivity and concordance than DEREK NEXUS. The battery system provided the best values of sensitivity and concordance among the three prediction methods, while its applicability was intermediate between those of the two individual methods, and it had the worst value of specificity among the three.

\section{Prediction of genotoxic potential of general industrial chemicals}

Table 4 summarizes the results of prediction of genotoxic potential of general industrial chemicals by DEREK NEXUS, ADMEWorks and the battery system. Again DEREK NEXUS showed the highest applicability $(100 \%)$, but the values of specificity, sensitivity and concordance were rather similar for DEREK NEXUS and ADMEWorks. The battery system provided the best values of sensitivity and concordance among the three prediction methods, but had the worst specificity.

\section{Prediction of mutagenic potential of INCI-listed chemicals}

Table 5 summarizes the results of prediction of mutagenic potential of INCI-listed chemicals by DEREK NEXUS, ADMEWorks and the battery system. DEREK NEXUS gave higher values of sensitivity, specificity, concordance and applicability than ADMEWorks. In particular, its applicability was $100 \%$. The battery system provided the best value of sensitivity among the three prediction methods, but it had the worst value of specificity.

\section{Prediction of genotoxic potential of INCI-listed chemicals}

Table 6 summarizes the results of prediction of genotoxic potential of INCI-listed chemicals by DEREK NEXUS, ADMEWorks and the battery system. The values of specificity and applicability with DEREK NEXUS were higher than those with ADMEWorks, while the values of sensitivity and concordance with ADMEWorks were higher than those with DEREK NEXUS. The battery system provided the best value of sensitivity among the three prediction methods, but had the worst values of specificity and concordance.

\section{Decision tree for genotoxicity evaluation system of cosmetic ingredients}

As shown in Fig. 1, we propose a decision tree for evaluating genotoxic potential of cosmetic ingredients. First, it is decided whether evaluation of a candidate cosmetic ingredient based on reported information is practicable or not. If it is practicable, judgment is made by an expert genotoxicologist. If it is impracticable, the next step is to decide whether the threshold of toxicological concern (TTC) level can be evaluated. If it can, then judgment is made by an expert genotoxicologist. If it cannot, an in silico method(s) is used to predict whether the candidate has genotoxic potential, and the candidate is evaluated with the aid of an expert genotoxicologist. If all these steps are impracticable, the candidate is evaluated by means of genotoxicity tests, with the aid of an expert if necessary.

\section{DISCUSSION}

There are many reasons why computational methodologies to predict the genotoxic potential of cosmetic ingredients are desirable. One of the most important of these reasons is the need to develop new genotoxicity evaluation systems that do not require the use of animals. In the European Union (EU), a marketing ban on cosmetics tested on animals has been in effect since the enactment of the 7 th amendment of the EU cosmetics directive in March 11, 2013 (EU, 2013). In response, there have been extensive collaborative studies among the European Centre for the Validation of Alternative Methods (ECVAM) in the EU, the Interagency Coordinating Committee on the Validation of Alternative Methods (ICCVAM) in the United States and the Japanese Centre for the Validation of Alternative Methods (JaCVAM) in Japan to develop alternatives to animal tests. Many in vitro toxicity tests have been established and have been incorporated into the Organization for Economic Cooperation and Development (OECD) test guidelines as alternatives to animal tests (OECD, 2004a, 2004b, 2013a, 2013b, 2013c, 2014a, $2014 \mathrm{~b}$ ). In addition, some in vitro genotoxicity tests had been established even before the collaborative studies started and used for the evaluation of genotoxic potential (OECD, 1997a, 1997b, 1997c). However, this shift towards evaluation by means of in vitro tests has serious implications for skilled manpower. The development of many in vitro tests, besides the combination of the Ames test and the CA test or the vit $\mathrm{MN}$ test, means that it is becoming difficult and expensive to comprehensively test large numbers of candidates within a reasonable period, although introduction of high-throughput in vitro assays may help to relieve this bottleneck.

Nonetheless, a prediction system for genotoxic potential of cosmetic ingredients by in silico computational methodologies may represent the best approach for rapid, low-cost, large-scale mutagenic hazard assessment, and in this connection, the ICH M7 guideline (ICH, 2014) provided a starting point. This guideline deals with assessment of hazard potential and control of DNA-reactive 
In silico prediction methods for genotoxicity of cosmetic ingredients

Table 3. Prediction of mutagenic potential of general industrial chemicals by DEREK NEXUS, ADMEWorks and the battery system.

A.

\begin{tabular}{lcccc}
\hline & \multicolumn{3}{c}{ Prediction by DEREK NEXUS } & \multirow{2}{*}{ Total } \\
\cline { 2 - 4 } & + & - & Inapplicable & \\
\hline Ames result $(+)$ & 217 & 32 & 0 & 249 \\
Ames result (-) & 15 & 78 & 0 & 93 \\
\hline Total & 232 & 110 & 0 & 342 \\
\hline
\end{tabular}

Sensitivity: $87 \%$ Specificity: $84 \%$ Concordance: $86 \%$ Applicability: $100 \%$

B.

\begin{tabular}{lcccc}
\hline & \multicolumn{3}{c}{ Prediction by ADMEWorks } & \multirow{2}{*}{ Total } \\
\cline { 2 - 4 } & + & - & Inapplicable & \\
\hline Ames result $(+)$ & 179 & 14 & 56 & 249 \\
Ames result (-) & 12 & 49 & 32 & 93 \\
\hline Total & 191 & 63 & 88 & 342 \\
\hline
\end{tabular}

Sensitivity: $93 \%$ Specificity: $80 \%$ Concordance: $90 \%$ Applicability: $74 \%$

C.

\begin{tabular}{lcccc}
\hline & \multicolumn{3}{c}{ Prediction by battery system } & \multirow{2}{*}{ Total } \\
\cline { 2 - 4 } & + & - & Inapplicable & \\
\hline Ames result (+) & 236 & 4 & 9 & 249 \\
Ames result (-) & 25 & 45 & 23 & 93 \\
\hline Total & 261 & 49 & 32 & 342 \\
\hline
\end{tabular}

Sensitivity: $98 \%$ Specificity: $64 \%$ Concordance: $91 \%$ Applicability: 91\%

The Ames test evaluation results of general industrial chemicals extracted from the literature (Kirkland et al., 2005; Ashby and Tennant, 1988, 1991) were compared to the prediction results by DEREK NEXUS (A), ADMEWorks (B) and the battery system (C).

Table 4. Prediction of genotoxic potential of general industrial chemicals by DEREK NEXUS, ADMEWorks and the battery system.

A.

\begin{tabular}{lcccc}
\hline & \multicolumn{3}{c}{ Prediction by DEREK NEXUS } & \multirow{2}{*}{ Total } \\
\cline { 2 - 4 } & + & - & Inapplicable & \\
\hline Genotoxicity result (+) & 267 & 18 & 0 & 285 \\
Genotoxicity result (-) & 26 & 31 & 0 & 57 \\
\hline Total & 293 & 49 & 0 & 342 \\
\hline
\end{tabular}

Sensitivity: 94\% Specificity: $54 \%$ Concordance: $87 \%$ Applicability: $100 \%$

B.

\begin{tabular}{lcccc}
\hline & \multicolumn{3}{c}{ Prediction by ADMEWorks } & \multirow{2}{*}{ Total } \\
\cline { 2 - 4 } & + & - & Inapplicable & \\
\hline Genotoxicity result (+) & 246 & 16 & 23 & 285 \\
Genotoxicity result (-) & 24 & 26 & 7 & 57 \\
\hline Total & 270 & 42 & 30 & 342 \\
\hline
\end{tabular}

Sensitivity: $94 \%$ Specificity: $52 \%$ Concordance: $87 \%$ Applicability: 91\%

C.

\begin{tabular}{lcccc}
\hline & \multicolumn{3}{c}{ Prediction by battery system } & \multirow{2}{*}{ Total } \\
\cline { 2 - 4 } & + & - & Inapplicable & \\
\hline Genotoxicity result $(+)$ & 282 & 3 & 1 & 285 \\
Genotoxicity result $(-)$ & 35 & 17 & 5 & 57 \\
\hline Total & 316 & 20 & 6 & 342 \\
\hline
\end{tabular}

Sensitivity: $99 \%$ Specificity: 33\% Concordance: $89 \%$ Applicability: 98\%

The genotoxicity (the Ames test and at least one of the CA test, the vitMN test or the MLA) evaluation results of general industrial chemicals extracted from the literature (Kirkland et al., 2005; Ashby and Tennant, 1988, 1991) were compared to the prediction results by DEREK NEXUS (A), ADMEWorks (B) and the battery system (C). 
Table 5. Prediction of mutagenic potential of INCI-listed chemicals by DEREK NEXUS, ADMEWorks and the battery system.

A.

\begin{tabular}{lcccc}
\hline & \multicolumn{3}{c}{ Prediction by DEREK NEXUS } & \multirow{2}{*}{ Total } \\
\cline { 2 - 4 } & + & - & Inapplicable & \\
\hline Ames result (+) & 14 & 3 & 0 & 17 \\
Ames result (-) & 2 & 22 & 0 & 24 \\
\hline Total & 16 & 25 & 0 & 41 \\
\hline
\end{tabular}

Sensitivity: $82 \%$

Specificity: $92 \%$

Concordance: $88 \%$

Applicability: $100 \%$

B.

\begin{tabular}{lcccc}
\hline & \multicolumn{3}{c}{ Prediction by ADMEWorks } & \multirow{2}{*}{ Total } \\
\cline { 2 - 4 } & + & - & Inapplicable & \\
\hline Ames result (+) & 8 & 2 & 12 & 22 \\
Ames result (-) & 2 & 15 & 2 & 19 \\
\hline Total & 10 & 17 & 14 & 41 \\
\hline
\end{tabular}

Sensitivity: $80 \%$

Specificity: $88 \%$

Concordance: $85 \%$

Applicability: $66 \%$

C.

\begin{tabular}{lccccc}
\hline & \multicolumn{3}{c}{ Prediction by battery system } & \multirow{2}{*}{ Total } & Sensitivity: $93 \%$ \\
\cline { 2 - 5 } & + & - & Inapplicable & & Specificity: $79 \%$ \\
Ames result (+) & 14 & 1 & 6 & 21 & \\
Ames result (-) & 4 & 15 & 1 & 20 & Concordance: $85 \%$ \\
\hline Total & 18 & 16 & 7 & 41 & Applicability: $83 \%$ \\
\hline
\end{tabular}

The Ames test evaluation results of INCI-listed chemicals extracted from the literature (Kirkland et al., 2005; Ashby and Tennant, 1988, 1991) were compared to the prediction results by DEREK NEXUS (A), ADMEWorks (B) and the battery system (C).

Table 6. Prediction of genotoxic potential of INCI-listed chemicals by DEREK NEXUS, ADMEWorks and the battery system.

A.

\begin{tabular}{lcccc}
\hline & \multicolumn{3}{c}{ Prediction by DEREK NEXUS } & \multirow{2}{*}{ Total } \\
\cline { 2 - 4 } & + & - & Inapplicable & \\
\hline Genotoxicity result (+) & 21 & 3 & 0 & 24 \\
Genotoxicity result (-) & 5 & 12 & 0 & 17 \\
\hline Total & 26 & 15 & 0 & 41 \\
\hline
\end{tabular}

Sensitivity: $88 \%$

Specificity: $71 \%$

Concordance: $80 \%$

Applicability: 100\%

B.

\begin{tabular}{lcccc}
\hline & \multicolumn{3}{c}{ Prediction by ADMEWorks } & \multirow{2}{*}{ Total } \\
\cline { 2 - 4 } & + & - & Inapplicable & \\
\hline Genotoxicity result (+) & 19 & 2 & 3 & 24 \\
Genotoxicity result (-) & 5 & 11 & 1 & 17 \\
\hline Total & 24 & 13 & 14 & 41 \\
\hline
\end{tabular}

Sensitivity: $90 \%$ Specificity: $69 \%$ Concordance: $81 \%$ Applicability: 66\%

C.

\begin{tabular}{lcccccc}
\hline & \multicolumn{3}{c}{ Prediction by battery system } & & \multirow{2}{*}{ Total } & Sensitivity: $92 \%$ \\
\cline { 2 - 5 } & + & - & Inapplicable & & Specificity: $50 \%$ \\
Genotoxicity result (+) & 22 & 2 & 0 & 24 & \\
Genotoxicity result (-) & 8 & 8 & 1 & 17 & Concordance: $75 \%$ \\
\hline Total & 30 & 10 & 1 & 41 & Applicability: $98 \%$
\end{tabular}

The genotoxicity (the Ames test and at least one of the CA test, the vitMN test or the MLA) evaluation results of INCI-listed chemicals extracted from the literature (Kirkland et al., 2005; Ashby and Tennant, 1988, 1991) were compared to the prediction results by DEREK NEXUS (A), ADMEWorks $(\mathbf{B})$ and the battery system of both $(\mathbf{C})$. 
In silico prediction methods for genotoxicity of cosmetic ingredients

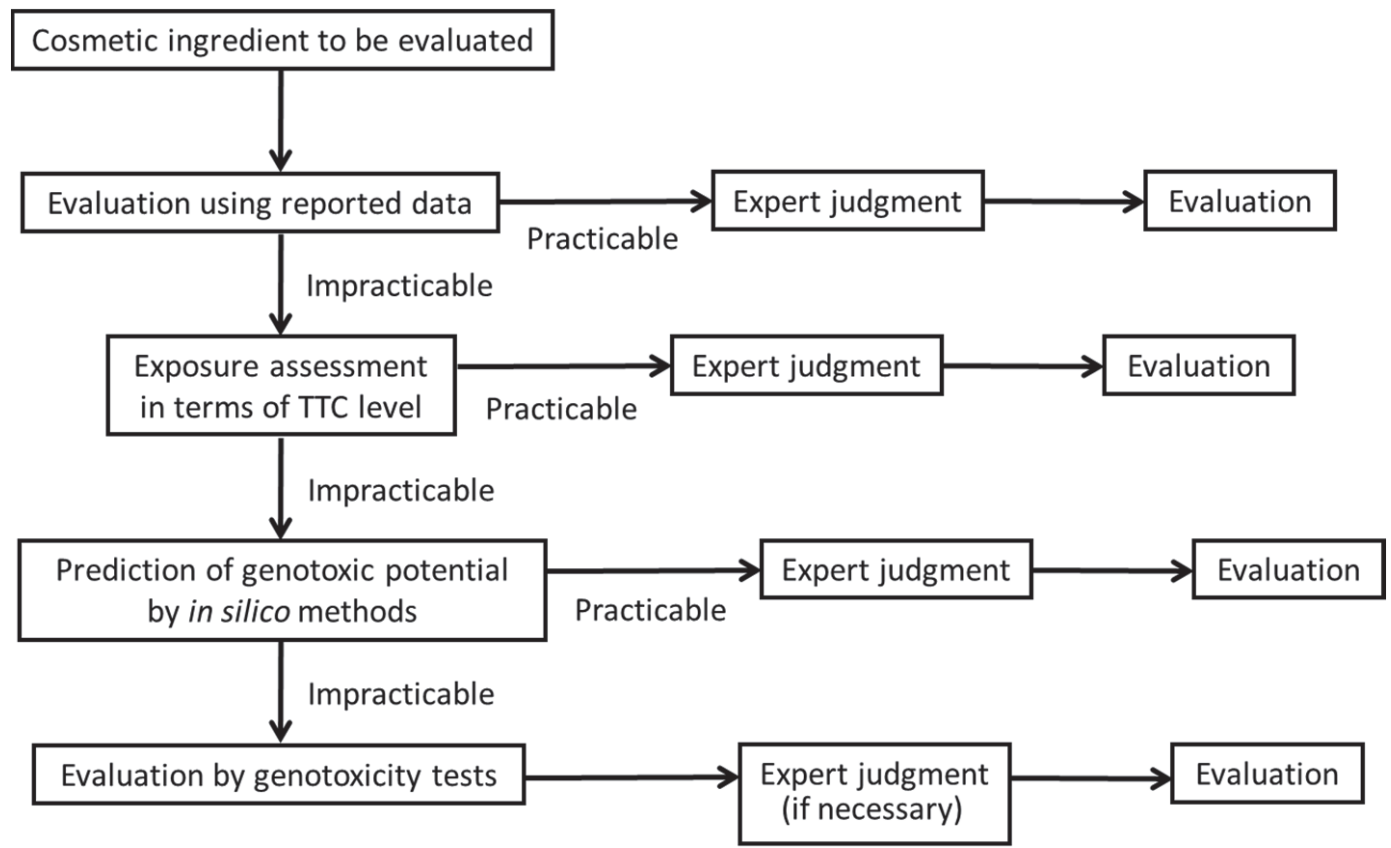

Fig. 1. Decision tree for evaluating genotoxic potential of cosmetic ingredients. Candidates as cosmetic ingredients are evaluated according to the flow in this decision tree proposed.

impurities in pharmaceuticals by means of the Ames test result prediction using in silico methods. We thought that it might be possible to apply in silico techniques to the prediction of not only mutagenic potential, but also genotoxic potential of cosmetic ingredients, if various kinds of genotoxicity endpoints are added to the system.

Here, we selected DEREK NEXUS and ADMEWorks as candidates for in silico prediction of genotoxicity taking into account the stipulations in the ICH M7 guideline (ICH, 2014) and the previous work of Hayashi et al. (2005) and Hayashi (2007). The ICH M7 guideline stipulates the use of two types of tools, i.e., an expert rulebased system and a statistics-based system, which complement each other. Hayashi et al. (2005) evaluated three commercially available in silico systems, i.e., DEREK NEXUS as an expert rule-based system, ADMEWorks as a statistics-based system, and MultiCASE as a database/ substructure-based system, using a data set extracted from the CGX database published by Kirkland et al. (2005) and the ECJ database evaluated in the Ministry of Health, Labour and Welfare (MHLW) project "Safety Examination of Existing Chemicals and Safety Programmes in Japan" (Hayashi et al., 2005). In the Ames test prediction, MultiCASE showed the highest value of concordance, but both DEREK NEXUS and ADMEWorks showed bet- ter applicability than MultiCASE. We considered that applicability is important, because our aim is to establish a prediction system especially for cosmetic ingredients, rather than general industrial chemicals. DEREK NEXUS is a popular tool because it features 748 alerts covering a wide range of toxicological endpoints in humans, other mammals and bacteria, as shown in Ver. 3.0.1. It should be noted, however, that Ver. 3.0.1 of DEREK NEXUS does not actually predict a negative response for any endpoint. Although the indication 'nothing to report' might seem to be a negative prediction, users are not informed if the query compound is not covered.

The battery system consisting of DEREK NEXUS and ADMEWorks showed improved sensitivity compared to DEREK NEXUS alone or ADMEWorks alone in the prediction of general industrial chemicals and the subset of the INCI-listed chemicals, but its specificity was decreased. This might be due to the excessive range of genotoxic endpoints obtained by combining the two methods. The battery system was introduced in order to complement the weak points of each individual tool, to avoid overlooking mutagenic and genotoxic potentials, but this might conversely have resulted in an increase of false positives. Although poor specificity might result in inappropriate elimination of candidate ingredients from 
development, this may be less critical than a low value of sensitivity, because a single false negative prediction for genotoxicity and/or carcinogenicity due to low sensitivity could have very serious consequences. As found in the work by Hayashi et al. (2005) and White et al. (2003), our battery system did not worsen the sensitivity.

The battery system might serve to reduce the number of false negatives. In the whole data set, false negative predictions of mutagenic potential were made for capsaicin, dibromoneopentylglycol, pentachloroanisole and urethane, and false negative predictions of genotoxic potential were made for capsaicin, $\alpha$-methylbenzyl alcohol and phenolphthalein. Among INCI-listed chemicals, the only false negative prediction of mutagenic potential was made for capsaicin, while false negative predictions of genotoxic potential were made for capsaicin and phenolphthalein. Although capsaicin is positive in the Ames test (Nagabhushan and Bhide, 1986), it is widely presumed not to be carcinogenic in humans on the basis of carcinogenicity studies in animals (Akagi et al., 1998; Bley et al., 2012). Thus, the apparently false negative prediction result of capsaicin by in silico methods might be a true negative. $\alpha$-Methylbenzyl alcohol is negative in the Ames test (Dieter, 1990), but positive in the CA test (Dieter, 1990). However, the positive result in the CA test was obtained at concentrations of more than $1 \mathrm{mg} / \mathrm{mL}$, which are an overdose according to the $\mathrm{ICH}$ guideline S2(R1) (ICH, 2011). $\alpha$-Methylbenzyl alcohol is carcinogenic in male rats (Dieter, 1990), but there is no clear evidence of carcinogenicity to humans (International Programme on Chemical Safety (IPCS), 2014), and its use as a fragrance is not considered to be a matter for concern (Scognamiglio et al., 2012; RIFM Expert Panel et al., 2012). Therefore, the apparently false negative prediction in the case of $\alpha$-methylbenzyl alcohol by in silico methods may also be a true negative. Phenolphthalein is not mutagenic in the Ames test (Mortelmans et al., 1986), but is clastogenic in the CA tests using Chinese hamster ovary cells (Witt et al., 1995) and Syrian hamster embryo cells (Tsutsui et al., 1997). It is carcinogenic to rodents (Dunnick and Hailey, 1996), is possibly also carcinogenic to humans, and is categorized in Group 2B of International Agency for Research on Cancer (IARC) (IARC, 2000). This chemical seems to be a non-genotoxic carcinogen based on these results. However, phenolphthalein is a weak acid, and has four tautomeric forms, depending on pH (Table 7) (Peters and Redmon, 1940). In the $\mathrm{pH}$ ranges of less than 0,0 to $8.2,8.2$ to 12.0 and more than 13.0, phenolphthalein takes a cationic form, a molecular form and two different anionic forms, respectively (Peters and Redmon, 1940). When we examined these forms by in silico methods, the molecular form of phenolphthalein was predicted as negative; however, DEREK NEXUS predicted carcinogenicity of the anionic form at $\mathrm{pH}$ 8.2.

There are some chemicals for which in silico prediction is difficult. For example, 4,4'-diphenylmethane diisocyanate is positive in the Ames test (Herbold et al., 1998), but it decomposes when dimethylsulfoxide is used as a vehicle in the Ames test, and the decomposition product accounts for the positive result (Herbold et al., 1998). The intrinsic mutagenic potential of 4,4'-diphenylmethane diisocyanate is negative. Basic Brown 17 is positive in the Ames test, but is negative in the vit MN test, the MLA,

Table 7. Structures of phenolphthalein at different $\mathrm{pH}$ ranges.

\begin{tabular}{lllll}
\hline Cas No. & Nothing to report & Nothing to report & Clastogenic & Carcinogenic \\
\hline Alerts in DEREK NEXUS & Positive in Ames & Negating to report \\
\hline Alerts in ADMEWorks & Negative & Negative & None
\end{tabular}

Phenolphthalein is a weak acid, and has four tautomeric forms depending on $\mathrm{pH}$. When the $\mathrm{pH}$ of phenolphthalein solution is in the ranges of less than 0,0 to 8.2, 8.2 to 12.0 and more than 8.2, phenolphthalein is predominantly in cationic form, molecular form and two anionic forms, respectively (Peters and Redmon, 1940). 
In silico prediction methods for genotoxicity of cosmetic ingredients

the HPRT assay and the Comet test in a 3D-reconstructed human skin model (Scientific Committee on Consumer Safety (SCCS), 2014). This chemical was finally evaluated as negative based on weight of evidence. Trimethyl phosphate was positive in the Ames test, but only at dose levels above the regulatory limit of $5 \mathrm{mg} /$ plate (Kirkland et al., 2005), and so this chemical should be regarded as negative. $m$-Cresidine and 2,4-difluoroaniline are mutagenic in the presence of hamster S9 but not rat S9 (Naven et al., 2010). These results seem to have contributed to the prediction of carcinogenic potential in humans. Although there are tools to predict drug metabolism, such as the tissue metabolism simulator (TIMES) (Mekenyan et al., 2004), it is hardly feasible to predict all the pathways of drug metabolism in detail. Thus, we have to consider the validity of the tests, taking account of the reactivity and stability of chemicals, as well as species difference, strain difference and gender difference of experimental animals.

Since good prediction results were obtained for INCIlisted chemicals, as described above, we also evaluated our in-house development candidates for cosmetic ingredients. The battery system showed high concordance values of more than $90 \%$ in the prediction of mutagenic potential and more than $85 \%$ in the prediction of genotoxic potential (unpublished data), suggesting that it would be useful for predicting mutagenic and genotoxic potential of novel cosmetic ingredients. However, it is possible that in silico methods might be more successful for predicting genotoxicity, as compared to other kinds of toxicity, because genotoxic or carcinogenic functional groups have been clarified to a considerable extent, as exemplified by 'Ashby's poly-carcinogen' (Ashby and Tennant, 1988; Miller and Miller, 1981).

It should be noted that the quality of the data set is critically important in the evaluation of in silico tools. Our data set was extracted from three reports (Kirkland et al., 2005; Ashby and Tennant, 1988, 1991), which had compiled data from the Carcinogenic Potency Database (CPDB), NTP, IARC, NCI and other publications. Therefore, we believe the database used here is reliable. We did not include the evaluation results of the vitMN test and the MLA in the data set when the evaluation result of the CA test existed in the data set. The reason for this is that the vitMN test was not widely used for evaluation of clastogenicity in comparison with the CA test before these reports were published, and the MLA is known to show low specificity. Although a new guideline for the vit $\mathrm{MN}$ test was recently published (ICH, 2011; OECD, 2014a), there was no previous guideline, and so some of the data might have been unreliable. We also examined a data set that included the evaluation results of the vitMN test and the MLA. Addition of these tests increased the number of positive evaluations of genotoxicity from 285 to 303 and decreased the number of negative results from 57 to 34 . This change reduced the specificity. In addition, we examined a data set that consisted of only the evaluation results of the Ames test and the CA test, but this also resulted in lower specificity (data not shown). Therefore, we adopted the procedure of including the evaluation results of the vitMN test and the MLA in the data set as tests for clastogenicity in cases where the evaluation result of the CA test was not available for a chemical, but not otherwise.

Although the tools that we used were effective in predicting mutagenicity and genotoxicity, they might also be available to predict the nature of a carcinogen, by changing the combination of endpoints. For example, carcinogens that are positive in the Ames test are referred to as genotoxic carcinogens, and have no threshold for carcinogenic activity (Fukushima et al., 2005). Thus, compounds that are positive in the $\mathrm{CA}$ test or the $\mathrm{MN}$ test might be genotoxic carcinogens if the Ames test is positive. But, if the Ames test is negative, these clastogenic chemicals might be non-genotoxic carcinogens that exhibit a threshold for carcinogenic activity (Fukushima et al., 2005). Since non-genotoxic carcinogens do not cause cancer at concentrations below the threshold, they might still be available for development as candidate ingredients at sufficiently low concentrations, where no carcinogenic risk is assured. On the other hand, carcinogenesis can be divided into three stages, i.e., initiation, promotion and progression (Klauning and Kamendulis, 2008). Initiation is defined as a mutational event causing a stable and heritable change, while promotion involves selective clonal expansion of initiated cells to produce a preneoplastic lesion, and progression involves the conversion of benign preneoplastic lesions into neoplastic cancer as a result of DNA damage arising from additional genotoxic events. Thus, initiation is a critical endpoint, and initiating activity would likely be a bar to development of a chemical. Considerations of cost and animal welfare mean that large-scale carcinogenicity testing is impossible, so evaluation of carcinogenicity by in silico methods would be extremely useful in the development of cosmetic ingredients.

A concern with the prediction of genotoxic potential by in silico methods is the maximal concentration limit in in vitro mammalian cell genotoxicity tests. The former ICH and OECD guidelines (ICH, 1995; OECD, 1997c) stipulated either $10 \mathrm{mmol} / \mathrm{L}$ or $5 \mathrm{mg} / \mathrm{mL}$ (whichever is lower) as the maximal concentration limit. However, this led to a high frequency of misleading positives, especially in the CA test (Kirkland et al., 2005). Un-physiologi- 
cal culture conditions, such as high concentrations of test chemicals, low $\mathrm{pH}$ or high osmolarity, contributed to this problem (Morita et al., 2012), and consequently guidelines are under revision or have been revised. In the case of the ICH guideline, the guidance on genotoxicity testing and data interpretation for pharmaceuticals intended for human use S2(R1) has reached the step 4 version, in which the maximum concentration limit recommended is $1 \mathrm{mmol} / \mathrm{L}$ or $0.5 \mathrm{mg} / \mathrm{mL}$ (whichever is lower). In the OECD, OECD Guideline 473 for the vitCA test (OECD, 2014b), and Guideline 487 for the vitMN test (OECD, 2014a), have been revised since September 26, 2014. In both guidelines, the maximum concentration limit is prescribed as $10 \mathrm{mmol} / \mathrm{L}$ or $2 \mathrm{mg} / \mathrm{mL}$ (whichever is lower). Differences in guidelines will clearly influence the evaluation results, and this remains a contentious issue.

There is still much work to be done to improve the quality of computational prediction of toxicity. For example, prediction of reproductive and developmental toxicity by in silico methods (Hosea and Jones, 2013) still shows low concordance. Better tools might be useful for highlighting potentially inconsistent experimental data that would require re-evaluation. It might also become possible to predict the genotoxic potential of currently unevaluable candidate ingredients, such as peptides, fermentation products, nano-materials, or crude products of animal or plant origin, and also to evaluate genotoxicity from the viewpoint of mechanisms. Although computational methodologies continue to improve, final evaluation will remain dependent upon the judgment of an expert with detailed knowledge of genotoxicity for a long time to come. We believe the decision tree proposed in this paper will be helpful to evaluate the genotoxic potential of cosmetic ingredients.

\section{ACKNOWLEDGMENTS}

The authors are grateful to W.R.S. Steele for his critical reading of the manuscript.

Conflict of interest---- The authors declare that there is no conflict of interest.

\section{REFERENCES}

Akagi, A., Sano, N., Uehara, H., Minami, T., Otsuka, H. and Izumi, K. (1998): Non-carcinogenicity of capsaicinoids in B6C3F1 mice. Food Chem. Toxicol., 36, 1065-1071.

Ames, B.N., Durston, W.E., Yamasaki, E. and Lee, F.D. (1973): Carcinogens are mutagens: A simple test system combining liver homogenates for activation and bacteria for detection. Proc.
Natl. Acad. Sci. USA, 70, 2281-2285.

Ashby, J. and Tennant, R.W. (1988): Chemical structure, Salmonella mutagenicity and extent of carcinogenicity as indicators of genotoxic carcinogenesis among 222 chemicals tested in rodents by the U.S. NCI/NTP. Mutat. Res., 204, 17-115.

Ashby, J. and Tennant, R.W. (1991): Definitive relationships among chemical structure, carcinogenicity and mutagenicity for 301 chemicals tested by the U.S. NTP. Mutat. Res., 257, 229-306.

Bley, K., Boorman, G., Mohammad, B., McKenzie, D. and Babbar, S. (2012): A comprehensive review of the carcinogenic and anticarcinogenic potential of capsaicin. Toxicol. Pathol., 40, 847873.

Contrera, J.F., Matthews, E.J. and Benz, R.D. (2003): Predicting the carcinogenic potential of pharmaceuticals in rodents using molecular structural similarity and E-state indices. Regul. Toxicol. Pharmacol., 38, 243-259.

de Groot, A.C. and Weijland, J.W. (1997): Conversion of common names of cosmetic allergens to the INCI nomenclature. Contact Dermatitis, 37, 145-150.

Dieter, M.P. (1990): Toxicology and carcinogenesis studies of alphamethylbenzyl alcohol in F344/N rats and B6C3F1 mice (gavage studies). National Toxicology Program (NTP), Technical Report Series No. 369, NIH Publication No. 89-2824, Department of Health and Human Services, Research Triangle Park, North Carolina.

Dunnick, J.K. and Hailey, J.R. (1996): Phenolphthalein exposure causes multiple carcinogenic effects in experimental model systems. Cancer Res., 56, 4922-4926.

EU (2013): The 7th Amendment (Directive 2003/15/EC) to the Cosmetic Directive (Directive76/768/EEC), Enforced: March 11, 2013, EU, Brussels.

Fukushima, S., Kinoshita, A., Puatanachokchai, R., Kushida, M., Wanibuchi, H. and Morimura, K. (2005): Hormesis and doseresponse-mediated mechanisms in carcinogenesis: Evidence for a threshold in carcinogenicity of non-genotoxic carcinogens. Carcinogenesis, 26, 1835-1845.

Greene, N., Judson, P.N., Langowski, J.J. and Marchant, C.A. (1999): Knowledge-based expert systems for toxicity and metabolism prediction: DEREK, StAR and METEOR. SAR QSAR Environ. Res., 10, 299-314.

Hayashi, M. (2007): Three Rs in mutation research. From in vivo to in silico evaluation. Altern. Animal Test. Experiment., 14, 9-13.

Hayashi, M., Kamata, E., Hirose, A., Takahashi, M., Morita, T. and Ema, M. (2005): In silico assessment of chemical mutagenesis in comparison with results of Salmonella microsome assay on 909 chemicals. Mutat. Res., 588, 129-135.

Hayashi, M., Kishi, M., Sofuni, T. and Ishidate, M.Jr. (1988): Micronucleus tests in mice on 39 food additives and eight miscellaneous chemicals. Food Chem. Toxicol., 26, 487-500.

Hayashi, M., Morita, T., Kodama, Y., Sofuni, T. and Ishidate, M.Jr. (1990): The micronucleus assay with mouse peripheral blood reticulocytes using acridine orange-coated slides. Mutat. Res., 245, 245-249.

Herbold, B., Haas, P., Seel, K. and Walber, U. (1998): Studies on the effect of the solvents dimethylsulfoxide and ethyleneglycoldimethylether on the mutagenicity of four types of diisocyanates in the Salmonella/microsome test. Mutat. Res., 412, 167-175.

Hillebrecht, A., Muster, W., Brigo, A., Kansy, M., Weiser, T. and Singer, T. (2011): Comparative evaluation of in silico systems for Ames test mutagenicity prediction: Scope and limitations. Chem. Res. Toxicol., 24, 843-854.

Hosea, N.A. and Jones, H.M. (2013): Predicting pharmacokinet- 
In silico prediction methods for genotoxicity of cosmetic ingredients

ic profiles using in silico derived parameters. Mol. Pharm., 10, 1207-1215.

IARC (2000): Phenolphthalein. In Some Antiviral and Antineoplastic Drugs, and Other Pharmaceutical Agents, Vol.76, pp.385-415, IARC, Lyon.

ICH (1995): Guidance on specific aspects of regulatory genotoxicity tests for pharmaceuticals, S2A, The ICH of Technical Requirements for Registration of Pharmaceuticals for Human Use, ICH Harmonised Tripartite Guideline, Step 4 version, 19 July 1995, ICH.

ICH (2011): Guidance on genotoxicity testing and data interpretation for pharmaceuticals intended for human use, S2(R1), The $\mathrm{ICH}$ of Technical Requirements for Registration of Pharmaceuticals for Human Use, ICH Harmonised Tripartite Guideline, Step 4 version, 9 November 2011, ICH.

ICH (2014): Assessment and control of DNA reactive (mutagenic) impurities in pharmaceuticals to limit potential carcinogenic risk, M7, The ICH of Technical Requirements for Registration of Pharmaceuticals for Human Use, ICH Harmonised Tripartite Guideline, Step 4 version, 23 June 2014, ICH.

IPCS (2014): $\alpha$-Methylbenzyl alcohol, INCHEM, Chemical Safety Information from Intergovernmental Organizations, Available at http://www.inchem.org/documents/jecfa/jecmono/v32je05.htm (Accessed November 28, 2014).

Ishidate, M.Jr., Miura, K.F. and Sofuni, T. (1998): Chromosome aberration assays in genetic toxicology testing in vitro. Mutat. Res., 404, 167-172.

Kirkland, D., Aardema, M., Henderson, L. and Müller, L. (2005): Evaluation of the ability of a battery of three in vitro genotoxicity tests to discriminate rodent carcinogens and non-carcinogens I. Sensitivity, specificity and relative predictivity. Mutat. Res., 584, 1-256.

Klauning, J.E. and Kamendulis, L.M. (2008): Chemical carcinogenesis. In Casarett and Doull's Toxicology, The Basic Science of Poisons, $7^{\text {th }}$ ed. (Klaassen, C.D., ed.), The McGraw-Hill Companies, Inc., New York.

Li, H., Chen, Z., Xu, X., Sui, X., Guo, T., Liu, W. and Zhang, J. (2011): Predicting human plasma protein binding of drugs using plasma protein interaction QSAR analysis (PPI-QSAR). Biopharm. Drug Dispos., 32, 333-342.

Martins, I.F., Teixeira, A.L., Pinheiro, L. and Falcao, A.O. (2012): A Bayesian approach to in silico blood-brain barrier penetration modeling. J. Chem. Inf. Model., 52, 1686-1697.

Matsushima, T., Hayashi, M., Matsuoka, A., Ishidate, M.Jr., Miura, K.F., Shimizu, H., Suzuki, Y., Morimoto, K., Ogura, H., Mure, K., Koshi, K. and Sofuni, T. (1999): Validation study of the in vitro micronucleus test in a Chinese hamster lung cell line (CHL/ IU). Mutagenesis, 14, 569-580.

McCann, J., Choi, E., Yamasaki, E. and Ames, B.N. (1975): Detection of carcinogens as mutagens in the Salmonella/microsome test: Assay of 300 chemicals. Proc. Natl. Acad. Sci. USA, 72, 5135-5139.

Mekenyan, O.G., Dimitrov, S.D., Pavlov, T.S. and Veith, G.D. (2004): A systematic approach to simulating metabolism in computational toxicology. I. The TIMES heuristic modelling framework. Curr. Pharm. Des., 10, 1273-1293.

Miller, E.C. and Miller, J.A. (1981): Searches for ultimate chemical carcinogens and their reactions with cellular macromolecules. Cancer, 47, 2327-2345.

Mori, M., Kobayashi, H., Sugiyama, C., Katsumura, Y. and Furihata, C. (1999): Induction of unscheduled DNA synthesis in hairless mouse epidermis by skin carcinogens. J. Toxicol. Sci.,
24, 217-226.

Morita, T., Honma, M. and Morikawa, K. (2012): Effect of reducing the top concentration used in the in vitro chromosomal aberration test in CHL cells on the evaluation of industrial chemical genotoxicity. Mutat. Res., 741, 32-56.

Mortelmans, K., Haworth, S., Lawlor, T., Speck, W., Tainer, B. and Zeiger, E. (1986): Salmonella mutagenicity tests: II. Results from the testing of 270 chemicals. Environ. Mutag., 8, Suppl. 7, 1-119.

Myshkin, E., Brennan, R., Khasanova, T., Sitnik, T., Serebriyskaya, T., Litvinova, E., Guryanov, A., Nikolsky, Y., Nikolskaya, T. and Bureeva, S. (2012): Prediction of organ toxicity endpoints by QSAR modeling based on precise chemical-histopathology annotations. Chem. Biol. Drug Des., 80, 406-416.

Nagabhushan, M. and Bhide, S.V. (1986): Nonmutagenicity of curcumin and its antimutagenic action versus chili and capsaicin. Nutr., Cancer, 8, 201-210.

Naven, R.T., Louise-May, S. and Greene, N. (2010): The computational prediction of genotoxicity. Expert Opin. Drug Metab. Toxicol., 6, 797-807.

OECD (1997a): Bacterial reverse mutation test, Test guideline 471, OECD Guideline for Testing of Chemicals, Adopted: 21 July 1997, OECD, Paris.

OECD (1997b): In vitro mammalian cell gene mutation test, Test guideline 476, OECD Guideline for Testing of Chemicals, Adopted: 21 July 1997, OECD, Paris.

OECD (1997c): In vitro mammalian chromosome aberration test, Test guideline 473, OECD Guideline for Testing of Chemicals, Adopted: 21 July 1997, OECD, Paris.

OECD (2004a): In vitro 3T3 NRU phototoxicity test, Test guideline 432, OECD Guideline for Testing of Chemicals, Adopted: 13 April 2004, OECD, Paris.

OECD (2004b): Skin absorption: In vitro method, Test guideline 428, OECD Guideline for testing of chemicals, Adopted: 13 April 2004, OECD, Paris.

OECD (2013a): Bovine corneal opacity and permeability test method for identifying i) chemicals inducing serious eye damage and ii) chemicals not requiring classification for eye irritation or serious eye damage, Test guideline 437, OECD Guideline for Testing of Chemicals, Adopted: 26 July 2013, OECD, Paris.

OECD (2013b): In vitro skin irritation: Reconstructed human epidermis test method, Test guideline 439, OECD Guideline for Testing of Chemicals, Adopted: 26 July 2013, OECD, Paris.

OECD (2013c): Isolated chicken eye test method for identifying i) chemicals inducing serious eye damage and ii) chemicals not requiring classification for eye irritation or serious eye damage, Test guideline 438, OECD Guideline for Testing of Chemicals, Adopted: 26 July 2013, OECD, Paris.

OECD (2014a): In vitro mammalian cell micronucleus test, Test guideline 487, OECD Guideline for Testing of Chemicals, Adopted: 26 September 2014, OECD, Paris.

OECD (2014b): In vitro mammalian chromosomal aberration test, Test guideline 473, OECD Guideline for Testing of Chemicals, Adopted: 26 September 2014, OECD, Paris.

Pearlstein, R.A., Vaz, R.J., Kang, J., Chen, X.L., Preobrazhenskaya, M., Shchekotikhin, A.E., Korolev, A.M., Lysenkova, L.N., Miroshnikova, O.V., Hendrix, J. and Rampe, D. (2003): Characterization of HERG potassium channel inhibition using CoMSiA 3D QSAR and homology modeling approaches. Bioorg. Med. Chem. Lett., 13, 1829-1835.

Peters, C.A. and Redmon, B.C. (1940): Phenolphthalein and methyl orange. J. Chem. Educ., 17, 525-528. 
M. Aiba née Kaneko et al.

Purchase, I.F., Longstaff, E., Ashby, J., Styles, J.A., Anderson, D., Lefevre, P.A. and Westwood, F.R. (1978): An evaluation of 6 short-term tests for detecting organic chemical carcinogens. Br. J. Cancer, 37, 873-959.

RIFM Expert Panel, Belsito, D., Bickers, D., Bruze, M., Calow, P., Dagli, M.L., Fryer, A.D., Greim, H., Miyachi, Y., Saurat, J.H. and Sipes, I.G. (2012): A toxicological and dermatological assessment of aryl alkyl alcohols when used as fragrance ingredients. Food Chem. Toxicol., 50, Suppl. 2, S52-S99.

SCCS (2014): Opinion on Basic Brown 17, COLIPA n ${ }^{\circ}$ B007, SCCS/1531/14 Revision of 18 June 2014, SCCS, Brussels.

Scognamiglio, J., Jones, L., Letizia, C.S. and Api, A.M. (2012): Fragrance material review on $\alpha$-methylbenzyl alcohol. Food Chem. Toxicol., 50, Suppl. 2, S124-S129.

Sobol, Z., Homiski, M.L., Dickinson, D.A., Spellman, R.A., Li, D., Scott, A., Cheung, J.R., Coffing, S.L., Munzner, J.B., Sanok, K.E., Gunther, W.C., Dobo, K.L. and Schuler, M. (2012): Development and validation of an in vitro micronucleus assay platform in TK6 cells. Mutat. Res., 746, 29-34.

Sugimura, T., Sato, S., Nagao, M., Yahagi, T., Matsushima, T., Seino, Y., Takeuchi, M. and Kawachi, T. (1976): Overlapping of carcinogens and mutagens. In Fundamentals of Cancer Prevention (Magee, P.N., Takayama, S., Sugimura, T. and Matsushima, T., eds.), pp.191-215, University Park Press, Baltimore.

Sutter, A., Amberg, A., Boyer, S., Brigo, A., Contrera, J.F., Custer, L.L., Dobo, K.L., Gervais, V., Glowienke, S., van Gompel, J., Greene, N., Muster, W., Nicolette, J., Reddy, M.V., Thybaud, V., Vock, E., White, A.T. and Müller, L. (2013): Use of in silico systems and expert knowledge for structure-based assessment of potentially mutagenic impurities. Regul. Toxicol. Pharmacol., 67, 39-52.

Thybaud, V., Dean, S., Nohmi, T., de Boer, J., Douglas, G.R., Glickman, B.W., Gorelick, N.J., Heddle, J.A., Heflich, R.H.,
Lambert, I., Martus, H.J., Mirsalis, J.C., Suzuki, T. and Yajima, N. (2003): In vivo transgenic mutation assays. Mutat. Res., 540, 141-151.

Tice, R.R., Agurell, E., Anderson, D., Burlinson, B., Hartmann, A., Kobayashi, H., Miyamae, Y., Rojas, E., Ryu, J.C. and Sasaki, Y.F. (2000): Single cell gel/comet assay: Guidelines for in vitro and in vivo genetic toxicology testing. Environ. Mol. Mutagen., 35, 206-221.

Tsutsui, T., Tamura, Y., Yagi, E., Hasegawa, K., Tanaka, Y., Uehama, A., Someya, T., Hamaguchi, F., Yamamoto, H. and Barrett, J.C. (1997): Cell-transforming activity and genotoxicity of phenolphthalein in cultured Syrian hamster embryo cells. Int. J. Cancer, 73, 697-701.

Wanchana, S., Yamashita, F. and Hashida, M. (2003): QSAR analysis of the inhibition of recombinant CYP $3 \mathrm{~A} 4$ activity by structurally diverse compounds using a genetic algorithm-combined partial least squares method. Pharm. Res., 20, 1401-1408.

White, A.C., Mueller, R.A., Gallavan, R.H., Aaron, S. and Wilson, A.G. (2003): A multiple in silico program approach for the prediction of mutagenicity from chemical structure. Mutat. Res., 539, 77-89.

Witt, K.L., Gulati, D.K., Kaur, P. and Shelby, M.D. (1995): Phenolphthalein: Induction of micronucleated erythrocytes in mice. Mutat. Res., 341, 151-160.

Worth, A., Fuart-Gatnik, M., Lapenna, S., Lo Piparo, E., MostragSzlichtyng, A. and Serafimova, R. (2011): The use of computational methods in the toxicological assessment of chemicals in food: Current status and future prospects, EUR-Scientific and Technical Research Reports, EUR 24748 EN, EU Joint Research Centre, Ispra.

Zeiger, E. (2001): Genetic toxicity tests for predicting carcinogenicity. In Genetic Toxicology and Cancer Risk Assessment (Choy, W.N., ed.), pp.29-46, Marcel Dekker, Inc., New York. 